\title{
Research on lung cancer and its funding, 2004-2018
}

\author{
Mursheda Begum ${ }^{1,2}$, Isobel Urquhart ${ }^{3}$, Grant Lewison ${ }^{2}$, Fouad Fouad ${ }^{4}$ and Richard Sullivan ${ }^{2 a}$ iD \\ ${ }^{1}$ Queen Mary University of London, Business School, Mile End Road, London E1 4NS, UK \\ ${ }^{2}$ King's College London, Institute of Cancer Policy, Guy's Hospital, London SE1 9RT, UK \\ ${ }^{3}$ University of Bristol, School of Geographical Sciences, University Road, Bristol BS8 1SS, UK \\ ${ }^{4}$ Faculty of Health Science, American University of Beirut, Beirut, Lebanon \\ ahttps://orcid.org/0000-0002-4493-1216
}

\begin{abstract}
Although smoking is declining in high-income countries, the relative burden from its most well-known consequence, lung cancer, continues to increase, especially in lowincome countries. We examined the amount, types, geographical origins and funding of research on lung cancer as revealed by papers in the Web of Science over the 15 years, 2004-2018. The annual number of lung cancer research papers increased over the study period from 2,157 to 8,202, but as a percentage of all biomedical research in Western Europe and North America they only accounted for one-eighth of the percentage of the disease burden. Lung cancer increased its share of cancer research from $4.4 \%$ to $6.5 \%$, mainly because of the greatly expanded output from China in 2014-2018 which published almost one-third of the world's total on a fractional count basis. For almost all other countries, their lung cancer presence in cancer research has declined over the 15 years. However, only $15 \%$ of the Chinese papers were co-authored internationally and its research was focussed on treatment rather than prevention. Support for lung cancer research is primarily from the government rather than charity. There is therefore an urgent need to increase support for lung cancer research, and for more international collaboration, especially in low-income countries where the disease burden is growing rapidly, and in neglected domains, such as screening and palliative care.
\end{abstract}

Keywords: lung cancer research, disease burden, research domains, funding

\section{Introduction}

Lung cancer remains the most burdensome manifestation of cancer in almost all countries, as measured by disability-adjusted life years (DALYs). This indicator comprises years of life lost to the disease (compared with life expectancy in Japan, currently the country with the highest value) plus years lived with a disability of given severity (estimated by the World Health Organization, WHO) as a number between zero and unity, the most severe. Lung cancer accounted for nearly $17 \%$ of the world cancer burden in 2015 and over 1.5\% of the total disease burden from all causes. (By way of comparison, breast, stomach and
Correspondence to: Grant Lewison Email: grantlewison@aol.co.uk

ecancer 2020, 14:1132

https://doi.org/10.3332/ecancer.2020.1132

Published: 03/11/2020

Received: 03/05/2020

Copyright: $@$ the authors; licensee ecancermedicalscience. This is an Open Access article distributed under the terms of the Creative Commons Attribution License (http:// creativecommons.org/licenses/by/3.0), which permits unrestricted use, distribution, and reproduction in any medium, provided the original work is properly cited. 
colorectal cancer each accounted for $8 \%$ of the total for all cancers in that year.) This percentage was 4.5\% in Western Europe and $4.0 \%$ in North America, where it was beginning to decline. It was much less in Africa (0.14\%) but had increased by $65 \%$ from the percentage burden in 2000. The countries with the highest percentages of all DALYs from lung cancer in 2015 were mostly in Europe (18 of the top 21), ranging from Hungary (6.3\%) to Norway (4.1\%). However, these were not the countries with the highest consumption of cigarettes (https://tobaccoatlas.org/topic/consumption/) because this is increasing rapidly in some countries, such as China (where over half the men smoke and two in every five cigarettes are smoked [1, 2]), and as a result, the death toll has not yet been fully manifested.

Although smoking is well-known as a main causative factor for lung cancer, an increasing number of these cancers are not so attributable [3]. The potential causes include genetics, notably the EGFR mutation [4] in Asian females. Other factors are residential radon [5], chronic obstructive pulmonary disease [6] and being underweight [7]. The effects of alcohol consumption are disputed: it seemed to have a positive effect on the disease in Spanish women [8], but a larger meta-analysis suggested that abstinence (as opposed to moderate consumption of wine or spirits) was not beneficial [9]. Second-hand smoke is certainly a causative factor [10], but will be declining as a result of the restrictions on smoking in public spaces that have been imposed in most high-income countries [11, 12]. Other measures, such as curbs on advertising, steep increases in cigarette prices and graphic warnings on packs of the health damage caused by smoking, are intended to help smokers to quit [13-22]. In combination, they have meant that in these countries the ratio between the percentages of all DALYs attributable to lung cancer in 2015 and in 2000 has only risen by $11 \%$. This compares with a 33\% worldwide increase, and a doubling in 23 countries, mostly low-income ones in Africa. In China, the percentage of all DALYs attributable to lung cancer has increased by $40 \%$ from $2.9 \%$ in 2000 to $4.1 \%$ in 2015 , and is likely to increase further as young women are starting to take up smoking [23]. Therefore, there is an increasing need for research to investigate the factors that lead to lung cancer, especially among never-smokers, means of screening and diagnosis and better treatments $[24,25]$.

Previous studies of cancer research have all demonstrated that lung cancer is relatively neglected within the cancer research portfolio compared with its share of the burden from all cancers. The shortfall from parity is of the order of 38\% in India [26], 50\% in China [27] and 75\% or more in 'western' and 'eastern' Europe [28, 29]. An earlier study [30] showed that lung cancer research represented about 5\% of all cancer research, and that it was slowly rising as a percentage. This study builds on that one and continues the analysis to 2018 . We have also investigated the sources of funding for lung cancer research.

\section{Methodology}

\section{Creation of the database of lung cancer (LUNCA) papers, outputs and research types}

We carried out a bibliometric analysis of research outputs worldwide during the 15 years (2004-2018) with a filter based on articles and reviews covered in the Web of Science (WoS, (c) Clarivate Analytics). The methodology for the selection of lung cancer papers was described previously [30]. We paid particular attention to the outputs of 25 leading countries (based on the number of papers) and determined the fractional presence of each one on all the papers in our database. For example, a paper with one French and two Chinese addresses would be categorised as $\mathrm{FR}=0.33$ and $\mathrm{CN}=0.67$. The countries are listed, with their ISO2 codes, in Table 1.

In order to put the lung cancer research outputs in context, they were compared with the outputs of biomedical research papers in the corresponding years (2014-2018) for the 25 countries, on an integer count basis. These were identified by means of another filter, based on address terms [31], which performed well in distinguishing between biomedical and non-biomedical papers in multidisciplinary journals, such as Nature and Science. The filter included the names of diseases, body parts and of places where medical research was undertaken, such as: AIDS or Bethesda or canc or Daiichi or eye or family or genet* or hepat* or INSERM.

The comparator was the percentage of the countries' disease burden in 2015 attributable to lung cancer, taken from WHO data. For these leading countries, we also compared their research outputs with their wealth, as measured by their gross domestic product (GDP). We plotted the number of papers (on a fractional count basis) in 2014-2018 with their GDPs in 2015.

We employed another macro to identify those papers that were of a particular research type (or domain) by means of sets of title words and journal name strings. These are described and listed by Begum et al [28]. Some papers could be classed in more than one domain; others were not classed in this way. 
Table 1. List of 25 leading countries in lung cancer research, with their ISO2 codes.

\begin{tabular}{|l|l|l|l|l|l|l|l|}
\hline \multicolumn{1}{|c|}{ Country } & ISO2 & \multicolumn{1}{|c|}{ Country } & ISO2 & \multicolumn{1}{c|}{ Country } & ISO2 & \multicolumn{1}{c|}{ Country } & ISO2 \\
\hline Australia & AU & France & FR & Japan & JP & Sweden & SE \\
\hline Austria & AT & Germany & DE & Korea (S) & KR & Switzerland & CH \\
\hline Belgium & BE & Greece & GR & Netherlands & NL & Taiwan & TW \\
\hline Brazil & BR & India & IN & Norway & NO & Turkey & TR \\
\hline Canada & CA & Iran & IR & Poland & PL & United Kingdom & UK \\
\hline China & CN & Italy & IT & Spain & ES & United States & US \\
\hline Denmark & DK & & & & & & \\
\hline
\end{tabular}

\section{Analysis of the funding of lung cancer research (LUNCA)}

Since 2009, the WoS has included funding information in the acknowledgement section in three searchable fields - funding organisations (FO), the grant number (FG) and full acknowledgment text (FX). However, the names of the funders are given in numerous different forms, so we gave codes to each funder so that their papers (and fractional contributions to their funding) could be identified [32]. Funding can be either explicit from the acknowledgment or implicit from the addresses. Organisations such as national labs, charity labs and commercial companies often support research in their own laboratories, so some of the addresses (in practice, about $15 \%$ ) also need to be coded. We listed the funding sources for lung cancer papers for the five years, 2009-2013, and coded them. A special Visual Basic (VBA) macro then provided codes for each of the funders on each paper. Another macro then analysed the funding of each country's papers. Not all papers had acknowledgments, either explicit or implicit. Such papers would be funded (in Europe) either by general health service funds to hospitals or general state funding of universities. We have not analysed these sources as they are typically not given as a result of a competitive peerreview process.

The main division of funding sources is into four sectors: government (central or local/regional), private non-profit (including collecting charities, endowed foundations, hospital and university own funds and other non-profits, such as professional associations and research institutes), commercial (including pharma/biotech and non-pharma) and international (e.g., the WHO and the European Union). We also identified the leading individual funders for lung cancer research in the five years, 2009-2013.

\section{Results}

\section{Volume of outputs, collaboration and research domains}

The volume of lung cancer research papers continued to expand in 2014-2018, and as a percentage of all cancer research, it actually increased from 4.4\% in 2004 to 6.5\% in 2018 (see Figure 1). There was a notable change in 2014-2018 from earlier years, mainly because of the much increased output from China, which grew overall from 49 papers in 2004 to 2960 in 2018 on a fractional count basis (see Figure 2). While the outputs from other countries only grew modestly, that of China expanded at a rate of about $30 \%$ per year. The result is that the Chinese output in 2014-2018 dominated the world production (see Figure 3). Together with the USA, Japan (JP) and South Korea (KR), it accounted for two-thirds of the world output in these years.

Figure 4 shows the comparison of the percentages of the leading countries' lung cancer research in 2014-2018 to their biomedical research outputs with the percentages of their disease burden attributable to lung cancer. Although India's (IN) output is proportionate, that of China is only half that level, and most Western European countries and those in North America publish between one-fifth and one-tenth the amount that the disease burden would justify. Figure 5 shows the comparison between lung cancer research outputs in the same years with countries' GDPs in 2015. The correlation is fairly good, with China, Japan, South Korea and Greece (GR) publishing about twice the amount expected. However, many European countries, notably Sweden (SE), Norway (NO) and Switzerland (CH) published only about half as much. Brazil (BR) published less than one-quarter of the expected amount. 


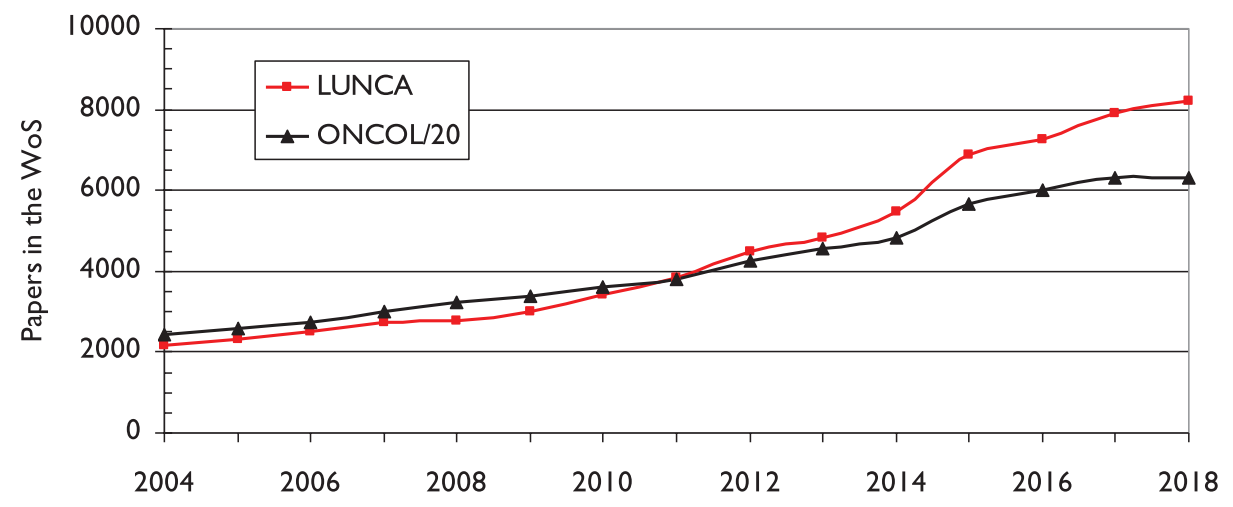

Figure 1. The volume of world-wide lung cancer research papers, and of all cancer research papers (divided by 20), 2004-18.

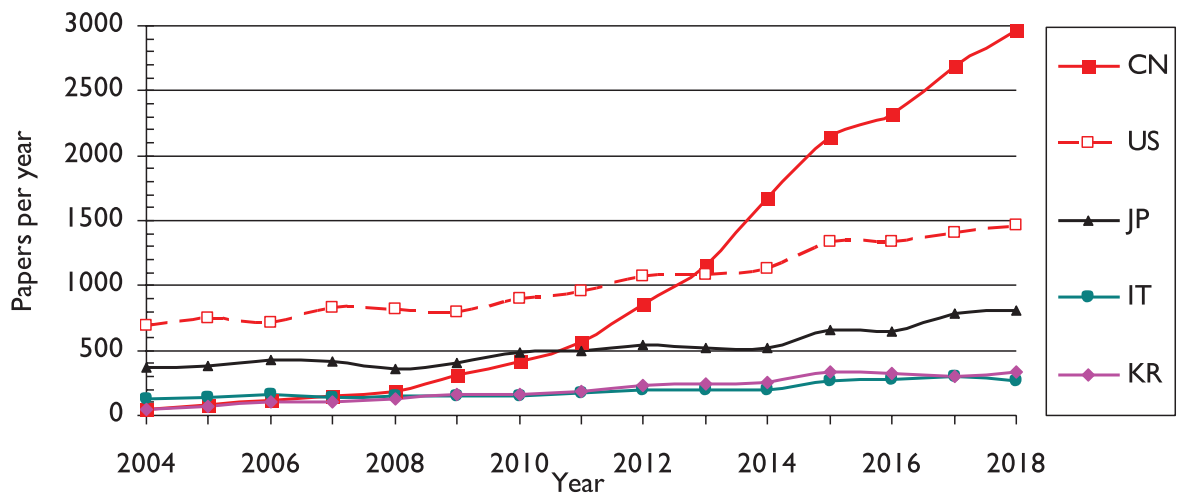

Figure 2. The outputs (fractional counts) of the five leading countries in lung cancer research, 2004-18. For ISO2 codes, see Table 1.

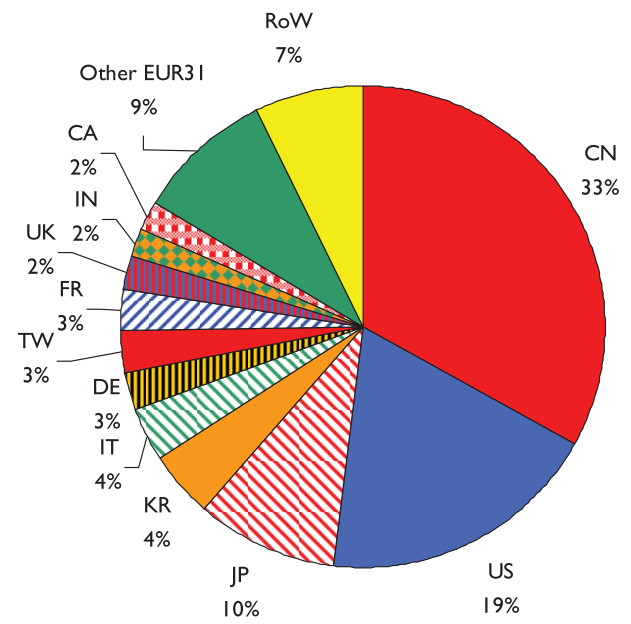

Figure 3. Pie diagram showing the contributions of the major countries to lung cancer research in 2014-18, fractional country counts. Country ISO2 codes are given in Table 1. 


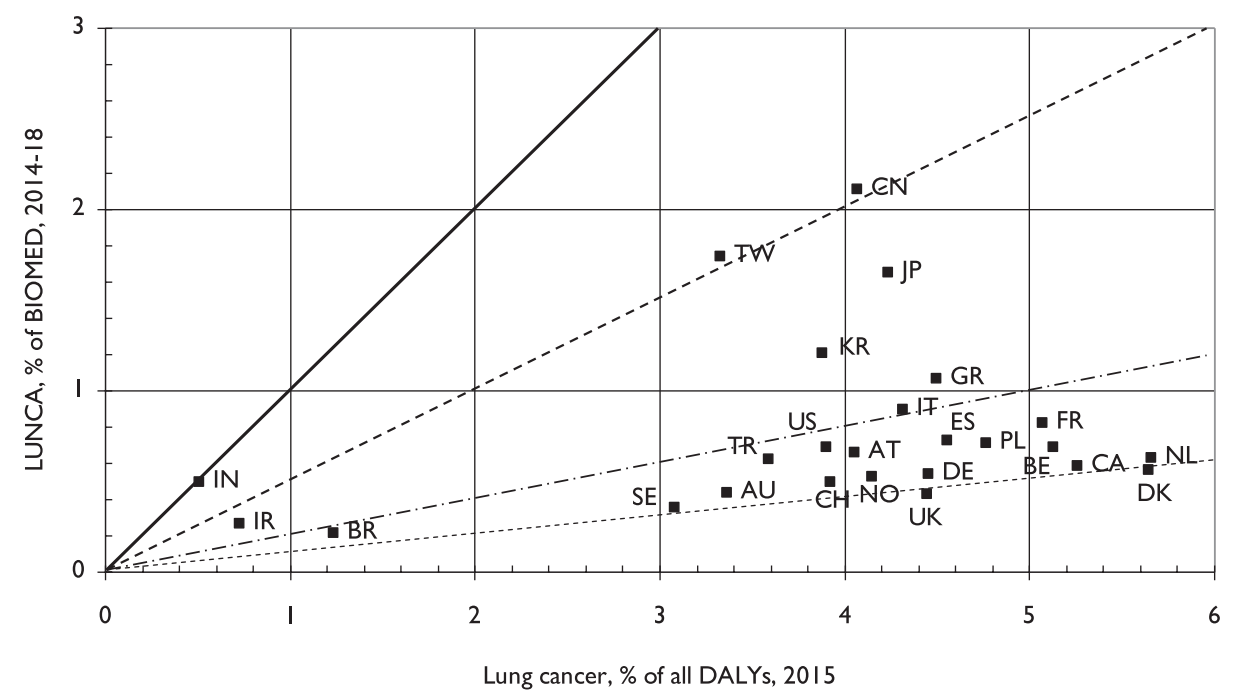

Figure 4. Comparison of the percentages of the leading countries' lung cancer research (LUNCA) to their biomedical research (BIOMED) outputs in 2014-18, integer counts, with the percentages of their disease burden from lung cancer in 2015. Country ISO2 codes are given in Table 1. Lines show equivalence, half, one fifth and one tenth the corresponding percentages.

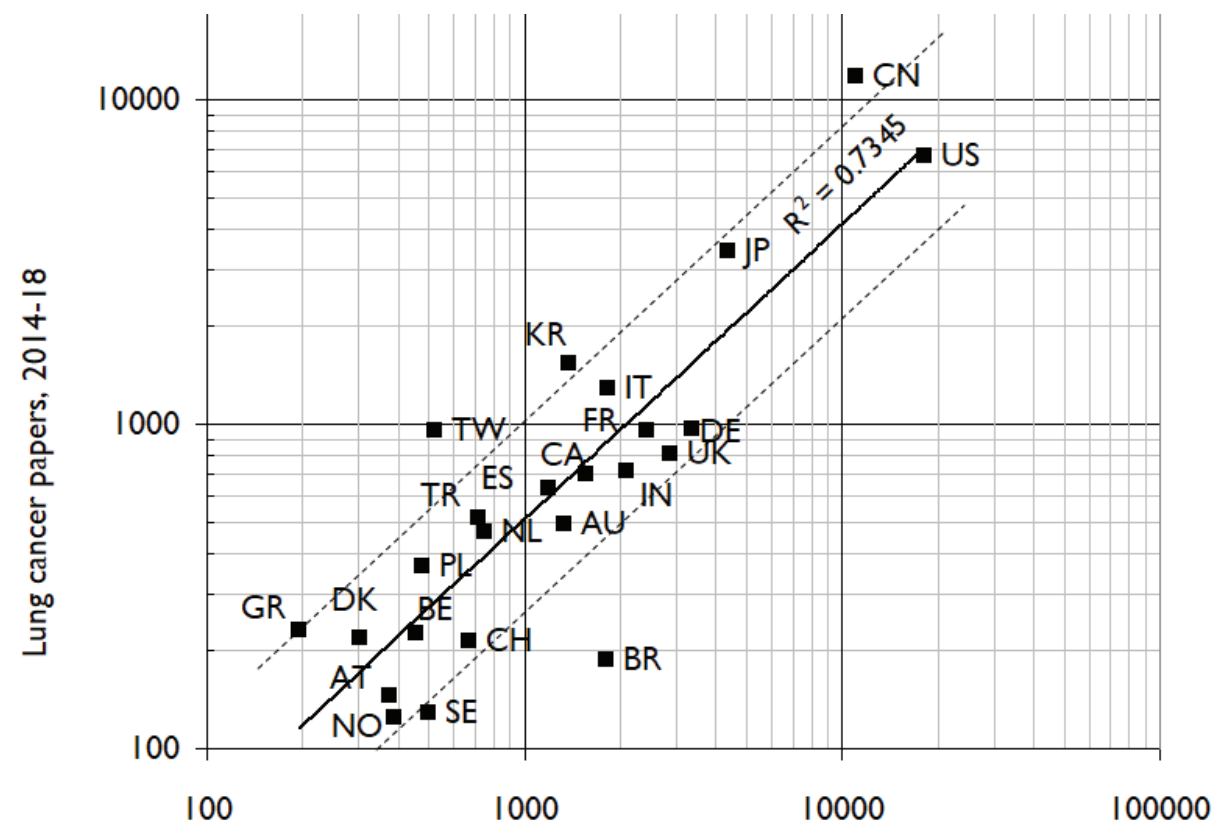

GDP, billion USD in 2015

Figure 5. Comparison of lung cancer research outputs in 2014-18 with countries' GDPs in 2015. Log-log scales. Country ISO2 codes are given in Table 1. Dashed lines show outputs twice and half the amounts expected on the basis of the least-squares correlation line. 
The types of research during the five years, 2014-2018, are shown in Figure 6. Genetics and prognosis are the main types of research undertaken. Drug treatment receives twice the amount of research as surgery and radiotherapy. However, there are significant variations in the relative amounts of work in the different research types or domains undertaken by the different countries (see Table 2). In order to show the countries' relative commitment more readily, Table 2 shows this for each country, where unity indicates that the country is performing the world average amount for the stated research type or domain. Some of the cells have been tinted to show particularly high (light or bright green) or low (yellow or pink) values, so as to make the figures that depart from the mean of unity stand out. China is notably weak in screening and palliative care, research types in which the USA is strong. Japan excels in surgery, but is also weak in screening, and Italy is weak in quality of life and palliative care, research types in which the UK is strong.

The differences in specialisation suggest that more international collaboration might help to improve the outputs of some countries which appear rather weak in the above table. The amount of such collaboration for these leading countries is shown in Table 3 . For China and the USA, there were 1414 collaborative papers with authors from both countries. They represented $11 \%$ of Chinese production (out of 12,730 papers) and $16 \%$ of US production (out of 8,802 papers). Of these 1,414 co-authored papers, only 19 (1.3\%) were on screening, six ( $0.4 \%)$ on palliative care and three $(0.2 \%)$ on quality-of-life; so there is clearly ample scope for more collaboration in these research domains.

\section{The funding of lung cancer research}

Figure 7 shows the number of papers from 24 leading countries based on fractional counts that had funding from the four main sectors in 2009-2013. Of the 19,644 papers published in the five years, 11,015 , or $56 \%$, had some acknowledged explicit or implicit funding. Sweden (SE) had by far the most funded papers (75\%) and Turkey (TR) had the least (13\%). China (CN) and Korea (KR) showed funding for two-thirds of their papers, Japan (JP) for $40 \%$ and Taiwan (TW) for only $30 \%$.

The major source of funds for lung cancer research was the government, with a total fractional contribution $(\mathrm{FC})$ equivalent to 5711 papers out of the fractional total of 18,556 papers from these countries, or $31 \%$ of the total, coming from this sector. The private non-profit (PNP) sector provided $14 \%$ of the total. The USA depended much more on the Federal Government for research support than from charitable sources, as did most other countries, except in Western Europe. The European countries with the most support from PNP sources, relative to that from the government, were Switzerland (ratio of $\times 3.2$ ), the Netherlands $(\times 2.1)$, Sweden and Italy $(\times 1.9)$ and Denmark $(\times 1.4)$. The ratios for Turkey and Greece were both more than seven, but these results are anomalous as neither had a large PNP sector and the amount of contestable support from the government was small.

Table 4 lists the main individual sources of support from the governmental and private non-profit sectors. There is some potential separated counting: for example, some acknowledgments credit the US National Cancer Institute (NCI) and some the US National Institutes of Health $(\mathrm{NIH})$. In practice, most of the support for lung cancer research from the $\mathrm{NIH}$ would have come from the $\mathrm{NCl}$. One ' $\mathrm{FC}$ ' amounts to the cost of one biomedical research paper, see below. Support from industry amounted to an average of $8 \%$ of the total, but US researchers received $40 \%$ of 1448 industrial FCs given to the 24 leading countries. However, industrial support was higher (as a fraction of total support) in Switzerland and Germany (16\%), Austria and the Netherlands (14\%), Canada (13\%) and the UK (11\%). In Table 5, the fractional contributions of the individual companies, and the groups of ones with generic codes, have all been added to give a composite industrial total for the 24 countries.

Figure 8 shows that support from the European Union (EU) was unevenly distributed, with the UK receiving the most (20 FCs), followed by Germany (14 FCs), France (13 FCs), the Netherlands (12 FCs) and Italy (11 FCs). However, in relation to their output, Poland (4.6\%), Sweden (4.4\%) and Austria (4.0\%) obtained the most support from the EU.

A previous study [33] that involved a survey of leading researchers in Europe to determine the costs of an individual biomedical research paper yielded an average figure (for 2013) of $€ 255,000$, but it varied with income per caput for three groups of countries. If we apply the formula relating average paper cost to income per caput, we can estimate the expenditure in the leading countries as in Table 6. The sum of the individual countries' research expenditures is $€ 961$ million. Allowing for the estimated 241 papers missing from the total output in that year at, approximately $€ 100,000$ per paper (as most of their researchers will be from low- and medium-income countries), we should add $€ 24$ million to give an estimated total of $€ 985$ million. In 2018 , with costs about $10 \%$ higher per paper, and an output of 8202 papers, the likely total research expenditure is about $€ 1.6$ billion rather than $€ 1.0$ billion. 


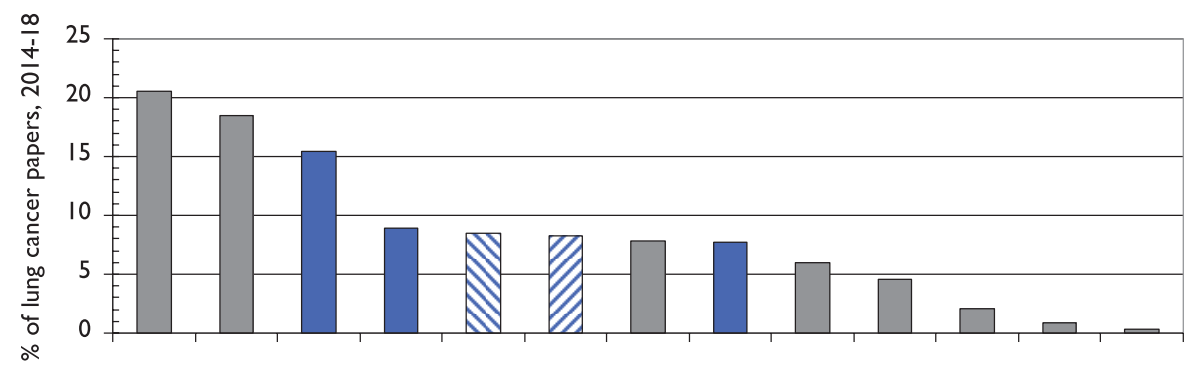

GENE PROG DRUG SURG TARG CHEM PATH RADI EPID DIAG SCRE PALL QUAL

Research type

Figure 6. Percentages of lung cancer research papers in 2014-18 represented by 12 types of research. Note: targeted therapy (TARG) and chemotherapy (CHEM) have been combined as "DRUG". Means of treatment shown as blue bars. GENE = genetics, PROG = prognosis, SURG = surgery, PATH = pathology, RADI =radiotherapy, EPID = epidemiology, DIAG = diagnosis, SCRE = screening, PALL = palliative care, QUAL = quality of life.

Table 2. Relative commitment of the leading countries to different types (for codes, see caption to Figure 6) of lung cancer research, 2014-18. Values $>2.0$ tinted bright green; values $>1.414$ tinted pale green; values $<0.707$ tinted pale yellow; values $<0.5$ tinted pink. Fractional counts of country addresses.

\begin{tabular}{|c|c|c|c|c|c|c|c|c|c|c|c|c|}
\hline & CHEM & DIAG & EPID & GENE & PALL & PATH & PROG & QUAL & RADI & SCRE & SURG & TARG \\
\hline $\mathrm{CN}$ & 1.20 & 0.84 & 0.89 & 1.33 & 0.40 & 1.11 & 1.05 & 0.53 & 0.57 & 0.31 & 0.59 & 0.82 \\
\hline US & 0.74 & 0.90 & 1.25 & 0.78 & 1.76 & 0.85 & 0.92 & 1.68 & 1.50 & 2.57 & 1.03 & 0.99 \\
\hline $\mathrm{KR}$ & 0.81 & 0.81 & 0.76 & 1.04 & 1.16 & 1.04 & 1.32 & 0.74 & 0.84 & 0.56 & 1.10 & 0.94 \\
\hline IT & 0.90 & 1.41 & 0.75 & 0.74 & 0.46 & 0.92 & 0.86 & 0.22 & 0.93 & 1.29 & 1.31 & 1.76 \\
\hline FR & 1.11 & 1.30 & 1.15 & 0.75 & 0.70 & 0.55 & 0.93 & 0.60 & 1.07 & 0.82 & 1.22 & 1.40 \\
\hline UK & 0.67 & 1.65 & 1.50 & 0.54 & 2.57 & 0.82 & 0.91 & 3.02 & 1.48 & 1.96 & 1.33 & 0.94 \\
\hline IN & 1.10 & 2.50 & 0.86 & 0.85 & 0.42 & 1.27 & 0.51 & 0.20 & 0.53 & 0.20 & 0.35 & 0.69 \\
\hline $\mathrm{CA}$ & 0.85 & 0.82 & 1.59 & 0.56 & 1.37 & 0.70 & 0.88 & 0.54 & 2.32 & 1.88 & 1.09 & 0.79 \\
\hline $\mathrm{PL}$ & 0.93 & 1.10 & 0.92 & 1.16 & 3.93 & 1.35 & 0.67 & 8.36 & 0.46 & 1.31 & 1.24 & 0.51 \\
\hline GR & 1.60 & 0.79 & 0.84 & 0.66 & 0.49 & 1.03 & 0.87 & 0.00 & 0.63 & 0.48 & 0.71 & 1.40 \\
\hline $\mathrm{BE}$ & 1.03 & 1.11 & 0.40 & 0.67 & 1.04 & 0.60 & 0.60 & 1.25 & 1.66 & 0.69 & 0.73 & 1.21 \\
\hline DK & 0.73 & 1.75 & 1.10 & 0.82 & 4.31 & 1.39 & 0.98 & 7.75 & 2.71 & 1.83 & 1.02 & 0.72 \\
\hline $\mathrm{CH}$ & 1.05 & 0.96 & 0.82 & 0.72 & 0.17 & 0.98 & 0.71 & 1.11 & 1.43 & 1.62 & 1.13 & 1.64 \\
\hline BR & 1.28 & 1.18 & 1.06 & 0.84 & 1.31 & 0.92 & 0.92 & 1.21 & 0.32 & 0.47 & 0.51 & 0.66 \\
\hline IR & 0.83 & 1.10 & 1.28 & 1.23 & 0.00 & 0.76 & 0.72 & 0.00 & 0.99 & 0.73 & 0.39 & 0.28 \\
\hline AT & 0.82 & 1.21 & 0.53 & 1.01 & 0.79 & 0.89 & 0.59 & 0.00 & 0.30 & 1.36 & 0.72 & 1.20 \\
\hline SE & 0.72 & 1.17 & 1.92 & 0.69 & 0.00 & 1.67 & 1.05 & 0.00 & 1.02 & 0.21 & 0.52 & 0.36 \\
\hline
\end{tabular}


Table 3. Amount of foreign contributions to the lung cancer research papers from the leading 25 countries in 2014-18. Country ISO2 codes are given in Table 1.

\begin{tabular}{|c|c|c|c|c|c|c|c|c|c|}
\hline ISO2 & \% foreign & ISO2 & \% foreign & ISO2 & \% foreign & ISO2 & \% foreign & ISO2 & \% foreign \\
\hline SE & 57.1 & NL & 45.7 & DE & 39.5 & IT & 29.2 & IN & 11.8 \\
\hline CH & 54.9 & CA & 41.7 & DK & 39.1 & PL & 26.9 & IR & 11.5 \\
\hline BE & 53.5 & NO & 41.1 & FR & 34.5 & US & 24.0 & JP & 9.8 \\
\hline AT & 52.3 & ES & 40.1 & GR & 30.5 & KR & 15.2 & CN & 7.3 \\
\hline UK & 46.4 & AU & 40.0 & BR & 30.5 & TW & 14.6 & TR & 6.7 \\
\hline
\end{tabular}
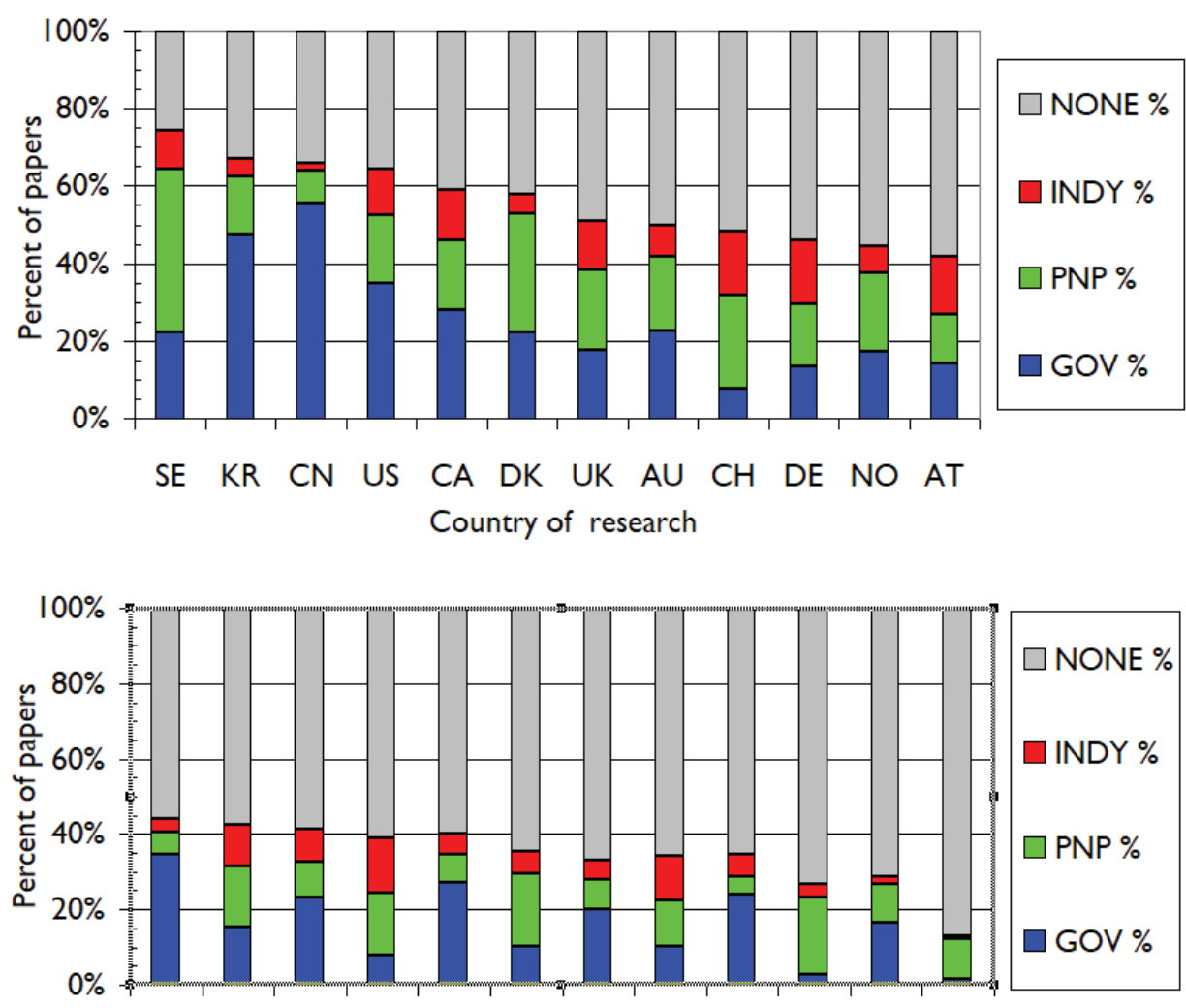

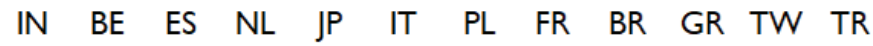

Country of research

Figure 7. Main funding sectors (GOV = government, PNP = private-non-profit, INDY = industry) for lung cancer papers from 24 leading countries, $2009-13$. For ISO2 codes, see Table 1. 
Table 4. List of leading national public sector and private-non-profit funders of lung cancer research, 2009-13, with their nationalities and fractional contributions.

\begin{tabular}{|c|l|c|c|l|l|}
\hline ISO & \multicolumn{1}{|c|}{ Funding organisation } & FCs & ISO & \multicolumn{1}{|c|}{ Funding organisation } & FCs \\
\hline CN & National Natural Science Foundation & 787 & US & Other charities (not ACS) & 97.1 \\
\hline US & National Cancer Institute & 687 & KR & Korean universities & 95.0 \\
\hline CN & Chinese provincial governments & 680 & JP & Japanese universities & 80.8 \\
\hline US & National Institutes of Health & 550 & TW & Taiwanese Government & 74.3 \\
\hline JP & Ministry of Education, Science \& Culture & 283 & IT & Assoc. Ital. Ricerca sul Cancro & 73.3 \\
\hline US & US universities & 248 & CN & Other governmental funders & 64.9 \\
\hline US & US non-profit associations & 204 & JP & Japanese endowed foundations & 61.5 \\
\hline US & US endowed foundations & 203 & KR & Ministry of Health \& Welfare & 60.8 \\
\hline JP & Ministry of Health and Welfare & 192 & US & Department of Defense & 58.2 \\
\hline KR & South Korean Government & 175 & US & Veterans Administration & 56.8 \\
\hline CN & Chinese universities & 155 & UK & National Inst. of Health Research & 49.5 \\
\hline KR & Ministry of Science and Technology & 129 & CA & Canadian Inst. for Health Res. & 48.6 \\
\hline JP & Society for Promotion of Science & 114 & US & American Cancer Society (ACS) & 48.6 \\
\hline CN & Key Program for Basic Research & 101 & CN & Ministry of Science \& Tech'y & 47.9 \\
\hline
\end{tabular}

Table 5. List of leading industrial funders of lung cancer research, 2009-13, with their codes, nationalities and fractional contributions (FCs). Final digraph codes as in Table 1.

\begin{tabular}{|l|l|c|l|l|l|}
\hline \multicolumn{1}{|c|}{ Funding code } & \multicolumn{1}{|c|}{ Funding organisation } & FCs & \multicolumn{1}{c|}{ Funding code } & \multicolumn{1}{c|}{ Funding organisation } & FCs \\
\hline X16-IP-US & US pharma companies & 170 & GNH-BT-US & Genentech Inc. & 25 \\
\hline LLL-IP-US & Eli Lilly Inc. & 124 & GSW-IP-UK & GlaxoSmithKline plc & 23 \\
\hline HLR-IP-CH & Hoffman LaRoche s.a. & 83 & AMN-BT-US & Amgen Inc. & 22 \\
\hline ZAT-IP-UK & AstraZeneca plc & 79 & X3B-BT-JP & JP biotech coys & 21 \\
\hline PFZ-IP-US & Pfizer Inc. & 74 & X76-IP-FR & FR pharma coys & 21 \\
\hline X1B-BT-US & US biotech companies & 66 & BMS-IP-US & Bristol Myers Squibb & 21 \\
\hline X36-IP-JP & JP pharma companies & 55 & MRK-IP-US & Merck Inc. (US) & 18 \\
\hline SLU-IP-FR & Sanofi Aventis s.a. & 43 & SMN-IN-DE & Siemens AG & 17 \\
\hline NVP-IP-CH & Novartis s.a. & 43 & BAY-IP-DE & Bayer AG & 16 \\
\hline X15-IN-US & US industrial companies & 42 & Z86-IP-KR & KR pharma coys & 15 \\
\hline BOI-IP-DE & Boehringer Ingelheim AG & 40 & CHG-IP-JP & Chugai Pharma Co & 14 \\
\hline X26-IP-DE & DE pharma companies & 36 & Z16-IP-CN & CN pharma coys & 14 \\
\hline VAR-IN-US & Varian Medical Systems & 27 & Z1B-BT-CN & CN biotech coys & 10 \\
\hline
\end{tabular}

IN = non-pharma company; IP = pharma company; BT = biotechnology company 


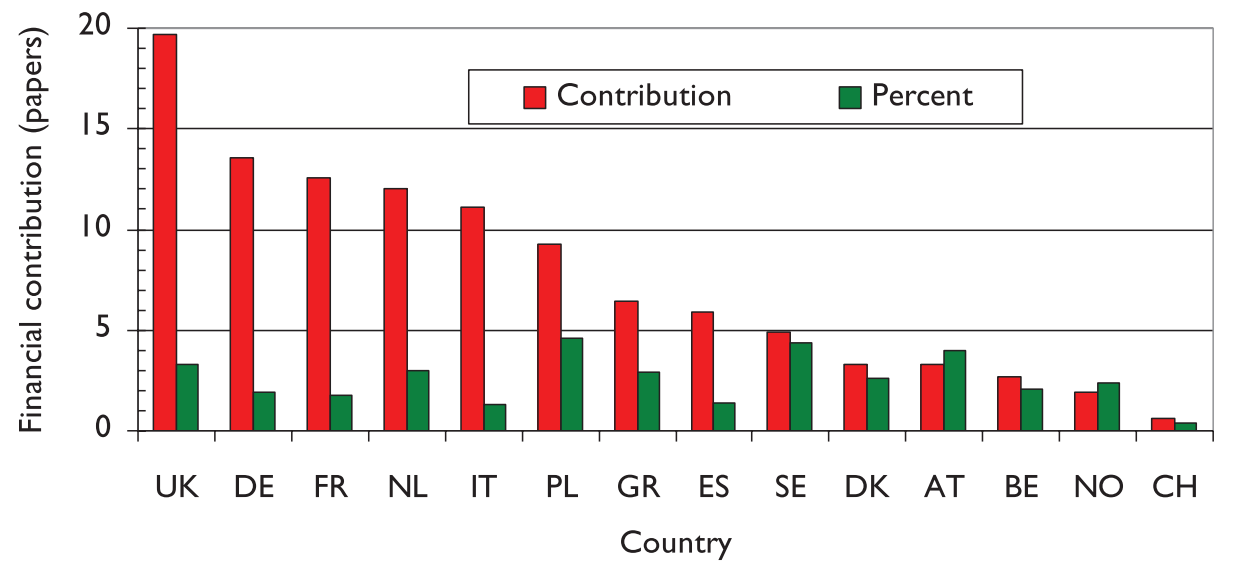

Figure 8. Support for lung cancer research from the European Union to 14 Member States in 2009-13.

Table 6. Estimates of the expenditure on lung cancer research in 2013 in the 24 leading countries. For ISO2 codes, see Table 1.

\begin{tabular}{|c|c|c|c|c|c|c|c|c|c|}
\hline ISO2 & $N$ & GDP/c. & CPP, $€$ k & $€ m$ & ISO2 & N & GDP/c. & CPP, €k & $€ \mathbf{m}$ \\
\hline US & 1,080 & 53,470 & 272 & 294 & TR & 98 & 10,970 & 131 & 13 \\
\hline JP & 524 & 46,330 & 248 & 130 & GR & 54 & 22,690 & 170 & 9 \\
\hline CN & 1,155 & 6,560 & 117 & 135 & AU & 70 & 65,400 & 311 & 22 \\
\hline IT & 195 & 35,620 & 213 & 41 & PL & 49 & 13,240 & 139 & 7 \\
\hline KR & 245 & 25,920 & 181 & 44 & IN & 52 & 1,570 & 100 & 5 \\
\hline DE & 164 & 47,250 & 251 & 41 & BE & 22 & 46,340 & 248 & 5 \\
\hline FR & 147 & 43,520 & 239 & 35 & CH & 35 & 90,680 & 395 & 14 \\
\hline UK & 133 & 41,680 & 233 & 31 & SE & 24 & 61,710 & 299 & 7 \\
\hline TW & 173 & 25,920 & 181 & 31 & DK & 34 & 61,670 & 299 & 10 \\
\hline CA & 118 & 52,210 & 268 & 32 & BR & 33 & 11,690 & 134 & 4 \\
\hline ES & 85 & 29,940 & 194 & 17 & NO & 14 & 102,700 & 435 & 6 \\
\hline NL & 82 & 51,060 & 264 & 22 & AT & 20 & 50,390 & 262 & 5 \\
\hline
\end{tabular}

$\mathrm{N}=$ number of papers (fractional counts), GDP/c. = wealth per caput, $\mathrm{CPP}, € \mathrm{k}=$ cost per paper, $€ \mathrm{~m}=$ estimated research expenditure

\section{Discussion}

It appears from Figure 4 that only India (IN) was publishing an amount of lung cancer research that was proportionate to its disease burden. China (CN) published about half the proportionate amount, but the USA and most European countries only published between one-fifth and one-tenth this amount. In view of the still increasing toll from the disease, this represents a substantial failure of most countries to tackle the problem.

As with other manifestations of cancer, there was a lack of research on palliative care for patients nearing the end of their lives. This can be a very difficult and unpleasant time as they struggle to breathe [34] and are concerned about distress to their families [35]. The only real hope, a lung transplant, remains out of reach for most of them. There may also be reluctance on the part of hospitals to treat smokers, some of whom are so addicted to their habit that they cannot give it up even when unmistakable signs of respiratory illness are present. Some 
countries are relatively active in this domain, such as Denmark, Poland the Netherlands and the UK, and it would be helpful if there were more international collaboration to spread best practices.

The study inevitably has some limitations. We were not able to calibrate the filter used to identify LUNCA papers, although it is likely to have high precision (over 0.9) because the ONCOL filter had a precision of 0.95 . The funding analysis was carried out earlier as part of our study of European cancer papers for the European Commission [29]. Updating it to cover 2014-2018 papers would have required much time and expenditure, which were not available. Third, our analysis has mainly been restricted to high- and upper-middle income countries where most biomedical research takes place, and we have not examined the situation in Africa, for example, where lung cancer is still a minor component of the disease burden, but is increasing rapidly.

\section{Conclusion}

There is an urgent need to increase support for lung cancer research, and for more international collaboration, especially in low-income countries where the disease burden is growing rapidly, and in neglected domains, such as screening and palliative care. As restrictions on smoking are applied increasingly, research needs to consider the other routes by which the disease is caused. There is less funding from government and industry than there is for research on other cancer anatomical sites.

\section{Acknowledgment}

This publication is funded through the UK Research and Innovation GCRF Research for Health in Conflict (R4HC-MENA); developing capability, partnerships and research in the Middle and Near East (MENA) ES/P010962/1. We are grateful to Philip Roe of Evaluametrics Ltd who wrote the macros used for the analyses.

\section{Conflict of Interest}

The authors declare that they have no conflict of interest.

\section{Funding}

This study was conducted with support of ESRC grant (ES/P010962/1) and an unrestricted grant from Roy Castle Lung Cancer Foundation, on behalf of the Global Lung Cancer Coalition of advocacy organisations. Roy Castle Lung Cancer Foundation receives unrestricted grants for the work of the Global Lung Cancer Coalition from Amgen, AstraZeneca, Boehringer Ingelheim, BMS, Lilly, Merck, Novartis, Pfizer, Roche and Takeda.

\section{References}

1. Liu SW, Zhang M, and Yang L, et al (2017) Prevalence and patterns of tobacco smoking among Chinese adult men and women: findings of the 2010 national smoking survey J Epidemiol Community Health 71(2) 154-161 https://doi.org/10.1136/jech-2016-207805 PMCID: 5284482

2. Zhang M, Liu S, and Yang L, et al (2019) Prevalence of Smoking and Knowledge About the Hazards of Smoking Among 170000 Chinese Adults, 2013-2014 Nicotine Tob Res 21(12) 1644-1651 https://doi.org/10.1093/ntr/ntz020 PMID: 30759252

3. Corrales L, Rosell R, and Cardona AF, et al (2020) Lung cancer in never smokers: The role of different risk factors other than tobacco smoking Crit Rev Oncol Hemato 148 https://doi.org/10.1016/j.critrevonc.2020.102895 
4. Ha SY, Choi SJ, and Cho JH, et al (2015) Lung cancer in never-smoker Asian females is driven by oncogenic mutations, most often involving EGFR Oncotarget 6(7) 5465-5474 https://doi.org/10.18632/oncotarget.2925 PMID: 25760072 PMCID: 4467161

5. Casal-Mourino A, Ruano-Ravina A, and Torres-Durán M, et al (2020) Lung cancer survival in never-smokers and exposure to residential radon: results of the LCRINS study Cancer Lett 487 21-26 https://doi.org/10.1016/j.canlet.2020.05.022 PMID: 32454144

6. Park HY, Kang D, and Shin SH, et al (2020) Chronic obstructive pulmonary disease and lung cancer incidence in never smokers: a cohort study Thorax 75(6) 506-509 https://doi.org/10.1136/thoraxjnl-2019-213732 PMCID: 7279186

7. Zhu HJ and Zhang SL (2018) Body mass index and lung cancer risk in never smokers: a meta-analysis BMC Cancer 18635 https://doi. org/10.1186/s12885-018-4543-y PMID: 29866064 PMCID: 5987408

8. Lavandra JAG, Ruano-Ravina A, and Kelsey KT, et al (2018) Alcohol consumption and lung cancer risk in never smokers: a pooled analysis of case-control studies Eur J Public Health 28(3) 521-527 https://doi.org/10.1093/eurpub/ckx196

9. Fehringer G, Brenner DR, and Zhang ZF, et al (2017) Alcohol and lung cancer risk among never smokers: A pooled analysis from the international lung cancer consortium and the SYNERGY study Int J Cancer 140(9) 1976-1984 https://doi.org/10.1002/ijc.30618 PMID: 28120396 PMCID: 5356930

10. Abdel-Rahman $O$ (2020) Incidence and mortality of lung cancer among never smokers in relationship to second hand smoking: findings from the PLCO trial Clin Lung Cancer 21(5) 415 https://doi.org/10.1016/j.cllc.2020.04.009 PMID: 32389507

11. Astell-Burt T, Zhang M, and Feng X, et al (2015) Geographical variation and correlates of tobacco smoking, second-hand smoke exposure, workplace tobacco prohibition, and pro-tobacco and counter-tobacco advertising in mainland China: a cross-sectional study of 98058 participants Lancet 38617 https://doi.org/10.1016/S0140-6736(15)00595-4

12. Nieminen $P$, Toljamo T, and Hamari A, et al (2010) Attitudes to new smoking restrictions and second-hand smoke among young Finnish males Scand J Public Health 38(8) 817-825 https://doi.org/10.1177/1403494810379892 PMID: 20688794

13. Trein $P$ (2017) Europeanisation beyond the European Union: tobacco advertisement restrictions in Swiss cantons J Public Policy 37(2) 113-142 https://doi.org/10.1017/S0143814X16000167

14. O'Neill D (2017) People love player's': cigarette advertising and the teenage consumer in post-war Britain 20 Century Br Hist 28(3) 414-439 https://doi.org/10.1093/tcbh/hwx015 PMID: 28922816

15. Cheng KW, Shang C, and Huang J, et al (2018) Association between point-of-sale advertising bans and cigarette smoking Tob Regul Sci 4(5) 20-29 https://doi.org/10.18001/TRS.4.5.2

16. Knuchel-Takano A, Hunt D, and Jaccard A, et al (2018) Modelling the implications of reducing smoking prevalence: the benefits of increasing the UK tobacco duty escalator to public health and economic outcomes Tob Control 27(E2) E124-E129 https://doi. org/10.1136/tobaccocontrol-2017-053860

17. Doogan NJ, Wewers ME, and Berman M (2018) The impact of a federal cigarette minimum pack price policy on cigarette use in the USA Tob Control 27(2) 203-208 https://doi.org/10.1136/tobaccocontrol-2016-053457

18. Tucker MR, Kivell BM, and Laugesen M, et al (2017) Changes to smoking habits and addiction following tobacco excise tax increases: a comparison of Maori, Pacific and New Zealand European smokers Aust N Z J Public Health 41(1) 92-98 https://doi.org/10.1111/17536405.12603

19. Kennedy RD, Hammond D, and Spafford MM, et al (2016) Educating smokers about the risk of blindness - insights to improve tobacco product health warning labels Tob Induced Dis 14 https://doi.org/10.1186/s12971-016-0094-7

20. Boshoff $C$ and Toerien $L$ (2017) Subconscious responses to fear-appeal health warnings: An exploratory study of cigarette packaging SA J Econ Manage Sci 20(1) https://doi.org/10.4102/sajems.v20i1.1630]

21. Shi ZH, Wang AL, and Emery LF, et al (2017) The importance of relevant emotional arousal in the efficacy of pictorial health warnings for cigarettes nicotine Tob Res 19(6) 750-755 https://doi.org/10.1093/ntr/ntw322 
22. Memish KE, Schüz N, and Frandsen M, et al (2017) Using self-affirmation to increase the effects of emotive health warnings on smoking: a randomized exploratory trial Nicotine Tob Res 19(10) 1238-1242 https://doi.org/10.1093/ntr/ntw167

23. Ho MG, Ma S, and Chai W, et al (2010) Smoking among rural and urban young women in China Tob Control 19(1) 13-18 https://doi. org/10.1136/tc.2009.030981 PMCID: 2921253

24. Fernandez-Villar A, Fernandez VL, and Botana-Rial M, et al (2010) The need for new techniques in the diagnosis and staging of lung cancer Arch Bronco 46(6) 336-338 https://doi.org/10.1016/j.arbes.2009.11.015

25. Spiro SG (2012) Screening for lung cancer: we still need to know more Thorax 67(4) 283-285 https://doi.org/10.1136/thoraxjnl-2011-201541 PMID: 22334533

26. Lewison G and Roe P (2012) The evaluation of Indian cancer research, 1990-2010 Scientometrics 93(1) 167-181 https://doi. org/10.1007/s11192-012-0633-9

27. Li A and Lewison G (2020) Chinese cancer research in 2009-18 and the disease burden Cancer Manage Res $125031-5040$ https://doi. org/10.2147/CMAR.S253276

28. Begum M, Lewison G, and Lawler M, et al (2018) Mapping the European cancer research landscape: an evidence base for national and Pan-European research and funding Eur J Cancer 100 75-84 https://doi.org/10.1016/j.ejca.2018.04.017 PMID: 30014883

29. Begum M, Lewison G, and Jassem J, et al (2018) Mapping cancer research across Central and Eastern Europe, the Russian Federation and Central Asia: implications for future national cancer control planning Eur J Cancer 104 127-136 https://doi.org/10.1016/j. ejca.2018.08.024 PMID: 30347288

30. Aggarwal A, Lewison G, and Idir S, et al (2016) The state of lung cancer research: a global analysis J Thorac Oncol 11(7) 1040-1050 https://doi.org/10.1016/j.jtho.2016.03.010 PMID: 27013405

31. Lewison G and Paraje G (2004) The classification of biomedical journals by research level Scientometrics 60(2) 145-157 https://doi. org/10.1023/B:SCIE.0000027677.79173.b8

32. Begum $M$ and Lewison G (2017) Web of science research funding information: methodology for its use in analysis and evaluation $J$ Sci Res 6(2) 65-73 https://doi.org/10.5530/jscires.6.2.12

33. Begum M, Lewison G, and Wright JS, et al (2016) European non-communicable respiratory disease research, 2002-13: bibliometric study of outputs and funding PLoS One 11(4) https://doi.org/10.1371/journal.pone.0154197

34. Weingärtner V, Scheve C, and Gerdes V et al (2014) Breathlessness, functional status, distress, and palliative care needs over time in patients with advanced chronic obstructive pulmonary disease or lung cancer: a cohort study J Pain Symptom Manage 48(4) 569-U5852 https://doi.org/10.1016/j.jpainsymman.2013.11.011

35. Ugalde A, Aranda S, and Krishnasamy M, et al (2012) Unmet needs and distress in people with inoperable lung cancer at the commencement of treatment Support Care Cancer 20(2) 419-423 https://doi.org/10.1007/s00520-011-1296-4 